\title{
Merleau-Ponty leitor de Schelling
}

\author{
Merleau-Ponty as Reader of Schelling
}

Rodrigo Benevides Barbosa Gomes

rodrigobenevides23@gmail.com

(Universidade Federal de São Carlos, São Paulo, Brasil)

\begin{abstract}
Resumo: Trata-se aqui de demonstrar - por meio das obras $O$ visível $e$ o invisivel e $A$ Natureza: Curso do Collège de France - a leitura merleau-pontiana da Naturphilosophie de Schelling. O fenomenólogo francês vê no idealista alemão um projeto que entra em harmonia com sua ontologia do Être Brut da década de 1950, pois, como o artigo demonstra, ambos defendem uma unicidade do Ser na qual o irrompimento da vida e da consciência são compreendidos como fenômenos que ultrapassam delimitações que separam natureza e cultura, positividade e negatividade, imobilidade e expressividade, etc. Com isso, o artigo visa indicar a convergência - explicitada pelo próprio Merleau-Ponty - entre as noções de Princípio Bárbaro e Carne.
\end{abstract}

Palavras-chave: Merleau-Ponty; Schelling; fenomenologia; ontologia.

\begin{abstract}
It is demonstrated - based on The Visible and the Invisible and Nature: Course Notes from the Collège de France - Merleau-Ponty's reading of Schelling's Naturphilosophie. The French phenomenologist sees in Schelling's project a confluence with his late 1950's ontology of Brute or Wild Being. As we shall demonstrate, both argue for a unicity of Being in which the emergence of life and consciousness must be understood as phenomena that exceeds demarcations that separate nature and culture, positivity and negativity, immobility and expressiveness, etc. Thus, the paper indicates the harmony - pointed out by Merleau-Ponty himself - between the notions of Barbarian Principle and Flesh.
\end{abstract}

Keywords: Merleau-Ponty; Schelling; phenomenology; ontology.

\section{Introdução}

No decorrer da década de 1950, Merleau-Ponty desenvolve sua chamada ontologia indireta, isto é, uma ontologia baseada na assimilação lateral do Ser pelo estudo de manifestações linguísticas, biológicas e subatômicas: "Merleau-Ponty mostra como as pesquisas da ciência contemporânea corroboram para uma nova compreensão do ser natural cujo alcance concerne à filosofia" (Ramos, 2013, p. 153). Mais precisamente, Merleau-Ponty trata de articular a linguística estruturalista inaugurada por Ferdinand de Saussure com os então recentes desdobramentos da biologia darwinista e da física da primeira metade do século XX. Merleau-Ponty bebe 
de tais fontes a fim de oferecer um conceito de natureza que ultrapasse formulações de cunho cartesiano oriundas da modernidade. A conexão que o fenomenólogo faz entre a filosofia de Alfred North Whitehead e os dados da mecânica quântica serve para ilustrar o tipo de esforço presente em sua obra tardia.

\begin{abstract}
A mecânica quântica, acredita o filósofo, ensina que, ao menos no nível subatômico, não há um conhecimento determinado pleno, pois nesse nível a probabilidade se manifesta como uma propriedade constituinte do ser. [...] Essa renovação das noções básicas da física (determinação, espaço e tempo) sugere uma ideia de natureza não mecanicista e não intelectualista. Merleau-Ponty se serve das reflexões de Whitehead para dar forma a essa nova ideia decorrente das teorias científicas contemporâneas (Sacrini, 2008, p. 97).
\end{abstract}

O que marca as obras de seus últimos anos é o detalhado exame de paradigmas da linguística, da biologia e da física para dar conta de uma renovada caracterização da physis. Mesmo que o uso de dados de diversas ciências seja comum a MerleauPonty desde a década de $1940^{1}$, sua preocupação ontológica torna-se ainda mais aguçada posteriormente, pois a descrição fenomenológica do Corpo Próprio ( cf. Merleau-Ponty, 1999) é acompanhada agora de uma investigação acerca do caráter sensível do próprio estofo do Ser, demonstrando assim a reversibilidade do vidente e do visível que há na existência como um todo. Em suma, o caráter pré-reflexivo da corporeidade humana é descrito como propriedade inerente ao Ser, isto é, trata-se agora de defender que "a intencionalidade aparece como interior ao Ser" (Moutinho, 2006, p. 403). Com isso, a década final do filósofo pode ser definida como um empreendimento que "levou Merleau-Ponty da fenomenologia à busca de uma ontologia do Ser Bruto, fonte da experiência e da razão antes que o pensamento reflexivo delas se aproprie" (Chauí, 2002, p. 197).

Como veremos adiante, Merleau-Ponty visa defender a noção de Carne como tecido ou elemento geral que perpassa a totalidade do Ser, o que implica na negação da divisão da natureza em partes extra partes, estabelecendo assim um entrelaçamento ou Quiasma que fundamenta a imbricação da existência manifestada no fenômeno da reversibilidade. Não há, devemos dizer, um completo descarte da ontologia presente n'A Estrutura do Comportamento (1942) e Fenomenologia da Percepção (1945), mas uma radicalização, ou melhor, um alastramento das propriedades que descrevem o Corpo Próprio, o que leva Ramos a afirmar que só assim podemos “compreender um dos movimentos maiores de seu pensamento: a passagem da centralidade do corpo próprio à centralidade da carne" (Ramos, 2013, p. 149, grifo da autora). Grosso modo, o conceito de natureza de seus últimos anos trata de expandir a descrição do Corpo Próprio para definir o caráter de Quiasma que configura a Carne do Ser. Como diz Ted Toadvine,

1 "O leitmotiv merleau-pontiano é sempre o mesmo: a busca de um acordo entre ciência e filosofia." (Moutinho, 2006, p. 276). 
A imagem do quiasma captura, para Merleau-Ponty, a lógica da relação entre o visível e o invisível, isto é, entre a sensibilidade e o sentir. O entrelaçamento da sensibilidade e do sentir é melhor ilustrado na reversibilidade do corpo humano, como quando uma mão toca a outra. Mas a reversibilidade da corporeidade humana é mais do que um mero exemplo para Merleau-Ponty; ela serve como o paradigma para uma espécie de imbricação que define o ser como tal. O quiasma, portanto, é a chave para a ontologia tardia de Merleau-Ponty e, particularmente, para o seu entendimento da relação entre humanos e natureza (Toadvine, 2009, p.107).

Para Merleau-Ponty, é impreterível - desde suas obras iniciais - se afastar de qualquer forma de cisão rígida entre Para-Si e Em-Si, querela essa que define seu distanciamento da fenomenologia de Sartre. Desse modo, apesar de uma indiscutível reformulação ontológica em seus escritos finais, não se pode asseverar uma ruptura irreconciliável em seu percurso filosófico. Como diz Chauí, é preciso lembrar que Merleau-Ponty "sustentou na totalidade de sua obra a crítica de dois enganos tenazes: o subjetivismo filosófico e o objetivismo científico, atitudes teóricas antagônicas que transformaram o para-si e o em-si em absolutos rivais" (Chauí, 2002, pp. 197-198). De ponta a ponta, Merleau-Ponty ofereceu "um pensamento que pusera em questão o estatuto do sujeito e do objeto” (idem, p. 4). Entretanto, apesar da indubitável continuidade de projeto observável em sua filosofia, deve-se igualmente notar que, por outro lado, a obra tardia parte "em direção a uma crítica mais profunda da ontologia do objeto” (Ramos, 2013, p. 149). Em seus últimos anos, ocorre uma inegável expansão de horizonte, levando-o a uma renovada fundamentação ontológica que permite Ramos afirmar que "o filósofo abandona a atitude de suas primeiras obras e passa a considerar que a expressão humana não é a rigor inédita, já que ela continua ou desdobra o simbolismo natural” (idem, p. 25, grifo nosso). Ramos defende reiteradamente em A Prosa de Dora (2013) que a ontologia indireta de MerleauPonty deve ser tomada como uma formulação diferenciada no conjunto de sua obra, tese que aceitamos aqui; porém, como dito, isso não significa a impossibilidade de conexão com as teses ontológicas da década de 1940, pois, como defende Toadvine, "A ontologia tardia de Merleau-Ponty pretende explicitar a ontologia subjacente em seus escritos iniciais" (Toadvine, 2009, p. 109). Para além de modificações teóricas introduzidas, há um norte que unifica a obra de Merleau-Ponty, a saber, a superação do dualismo cartesiano. Dito isso, é o próprio Merleau-Ponty que percebe os limites da sua ontologia inicial ao notar que a esfera humana - na imagem do cogito tácito - foi descrita demasiadamente apartada da natureza (cf. Moutinho, 2012). Resta, então, posicionar a intencionalidade no seio natural para evitar resquícios dualistas, já que "poderíamos dizer que as formulações das primeiras obras de Merleau-Ponty - e o peso que davam ao ineditismo da estrutura simbólica - faziam do surgimento do homem um acontecimento estrondoso que só reiterava a ideia clássica de uma natureza plena e objetiva" (Ramos, 2013, p. 154). É esse o erro que Merleau-Ponty 
visa remediar ao repensar a peculiaridade do homem dentro do quadro da natureza (cf. Bimbenet, 2004) e a tese de uma familiaridade ontológica primordial pensada como Carne é a última solução oferecida antes de sua morte prematura: "a ontologia indireta de Merleau-Ponty cumpre a promessa de revelar uma familiaridade originária entre a experiência humana e as estruturas ontológicas do mundo" (Sacrini, 2008, p. 223).

Desde Husserl, a análise da produção de sentido no bojo da natureza é tema vinculado à fenomenologia, demonstrando novamente que o autor francês, no fundo, não se distancia efetivamente de suas origens. A redução fenomenológica - além de demonstrar o papel ativo do Para-si na gênese do sentido ou da Gestalt - nos leva à noção de natureza como berço da significação e, por esse prisma, percebe-se que na ontologia indireta não há nada de tão estranho assim à tradição husserliana em termos de tópicos de investigação. Ramos nota que "Merleau-Ponty assume uma perspectiva de reflexão que já é apontada pela fenomenologia de Husserl [...] a discussão sobre a produtividade natural - à medida que enseja uma ontologia indireta - é o resultado de um desenvolvimento consequente da própria fenomenologia” (Ramos, 2013, p. 161). Porém, mesmo com esta ressalva, deve-se novamente admitir a presença, nas obras tardias, de uma consideração diferenciada sobre a esfera humana ou simbólica, indicando assim uma ontologia reformulada e, por conseguinte, um distanciamento da ontologia da década de 1940. Quando olhamos mais de perto a ontologia descrita em A Estrutura do Comportamento, diz Renaud Barbaras, fica claro que "a dificuldade encontra-se no estatuto da ordem simbólica, cuja relação com as camadas anteriores, enraizadas na vida, não é nada óbvia” (Barbaras apud Ramos, 2013, p. 14). É essa lacuna que Merleau-Ponty tenta resolver em sua ontologia tardia para, enfim, ultrapassar quaisquer traços dualistas. Em suma, ao tentar refinar sua ontologia e amarrar as pontas soltas das obras anteriores, Merleau-Ponty argumenta que a multiplicidade, isto é, as diversas manifestações particulares do Ser são, no fundo, desdobramentos de uma mesma Carne ou modalidade de ser, diferindo apenas em grau e não qualidade, levando-o a uma concepção de natureza harmoniosa com as oferecidas por autores como Whitehead (1979), William James (1988) e aquele que nos interessa no presente artigo: Friedrich Schelling (1860).

Schelling não é de forma alguma finalista ou vitalista. Para ele não há diferença essencial entre a Natureza orgânica e a Natureza inorgânica. "Não existe Natureza inorgânica em si”, diz ele, querendo mostrar assim que não há ruptura entre os seres organizados e as qualidades sensíveis (as quais também têm uma organização). Não há nem ruptura nem mesmo expressão comum. São duas Potenzen, duas "potências" diferentes da mesma Natureza. O desenvolvimento da Natureza consiste em que o superior é elevado a uma potência superior, não por supressão, mas por elevação. É por um desenvolvimento interno, e não por uma ruptura, que se passa do ser físico ao ser vivo. Se considerarmos produtos finitos como o enxofre e o cão, há entre eles diferenças de organização que a reflexão pode fornecer, mas há sobretudo um mesmo 
produto elevado a duas potências diferentes de organização, e trata-se de encontrar a qualidade percebida concentrando nosso pensamento nessa experiência, tal como se apresenta (Merleau-Ponty, 2006a, pp. 65-66).

Dito de outro modo, "na esteira de Schelling, o filósofo francês entende que entre a cultura e a natureza há uma continuidade simbólica” (Ramos, 2013, p. 187). Para Merleau-Ponty, trata-se de rechaçar qualquer ontologia que tente descrever o homem como um ser de propriedades inéditas que não possua lastro na natureza como tal. A esfera cultural, portanto, passa por uma espécie de naturalização e, com isso, o próprio caráter intencional do Para-si encontra agora suas raízes na physis, pois agora "passa a ser preciso deixar de pensar a intencionalidade como privilégio da consciência, já que ela atravessa o ser sensível” (idem, p. 176).

Vale ressaltar que, assim como no uso que Merleau-Ponty faz de Whitehead e da noção husserliana de Terra (Erde), a ontologia presente nos Cursos do Collège de France (1968) e nas notas inacabadas que compõem $O$ visível e o invisível (1964) não deve ser entendida como pura e simples transposição ou reciclagem da Naturphilosophie de Schelling. Além do fato de, à época, Merleau-Ponty não possuir acesso à obra completa do filósofo alemão (cf. Nogueira, 2019), há, inevitavelmente, inúmeros pontos de desacordo entre os autores que não permitem a mera equivalência entre suas respectivas noções de natureza. No entanto, o intuito aqui é detalhar a apropriação de Merleau-Ponty e realçar a harmonia entre ambos, demonstrando aquilo compartilhado nas teses ontológicas subjacentes aos seus conceitos de physis. Desse modo, o propósito do artigo não é exaurir suas respectivas filosofias para, enfim, compará-las. A presente pesquisa visa tão somente apresentar a leitura merleaupontiana de Schelling e, mesmo quando as fontes originais do filósofo alemão são apresentadas, trata-se aqui de utilizá-las apenas como auxílio para refazer o percurso merleau-pontiano, ou seja, nas páginas seguintes o leitor encontrará o Schelling de Merleau-Ponty.

Dito isso, o artigo se divide da seguinte maneira: primeiramente, demonstrase a confluência entre as ontologias de Merleau-Ponty e Schelling; em seguida, apresenta-se a possibilidade de aproximação entre as noções de Carne e Princípio Bárbaro.

I.

Para além do uso dos dados científicos disponíveis em seus respectivos contextos históricos, a ontologia indireta de Merleau-Ponty e a Naturphilosophie de Schelling defendem que o vislumbre do Absoluto ocorre primordialmente no Unbewusste, isto é, no domínio pré-reflexivo do Eu. Ao examinar a filosofia do alemão, MerleauPonty nos lembra que Schelling enxerga um limite nas teses reflexivas ao reconhecer 
a reconciliação entre natureza e espírito expressa na noção de erste Natur que marca o período de Jena: “O que inspira a Schelling essa ideia de erste Natur é a oposição às filosofias reflexivas, para as quais o Ser é contemporâneo da reflexão, é o sentimento de que o Ser é anterior a toda reflexão sobre o Ser, e de que reflexão vem em segundo lugar” (Merleau-Ponty, 2006a, p. 60). O Princípio Bárbaro de Schelling, como veremos mais adiante, pode ser compreendido como a Carne que define o Être Brut merleau-pontiano. As formulações de ambos apontam para um aspecto primordial ou originário da physis onde não há oposição ou compartimentalização de noções como mente, matéria, negatividade, imobilidade, ser, não-ser, etc. Não há uma natureza inerte onde, por razões estritamente randômicas, se irrompe características qualitativas associadas à esfera vivente. O surgimento da vida deve ser tomado como desdobramento de um princípio que já perpassa a totalidade, uma pulsão contínua de produtividade que fundamenta os entes particulares. Para que fique claro: não há vitalismo (o que pressupõe dualismo) nas teses de Merleau-Ponty e Schelling. Quando se fala em princípio ou pulsão produtiva, não há de modo algum a tese de algo imaterial destacado ou ontologicamente distinto, isto é, um nous que, de alguma maneira, tomaria posse da matéria e, ainda por cima, definiria o norte de uma suposta evolução cósmica. Como lembra Merleau-Ponty, "Schelling repugna essa maneira de pensar teleológica, que the parece destruidora da ideia de Natureza" (idem, p. 67). Com isso, talvez a definição contemporânea que mais se aproxima para caracterizá-los seria - sem excluir as possíveis ressalvas que não trataremos aqui - a de pampsiquismo, categoria comumente associada a autores do final do século XIX e começo do século XX como William James e Alfred Whitehead. 0 termo, que pode soar enganoso à primeira vista, obviamente não defende uma homogeneização do Ser que o retrataria como um continuum de experiências sencientes. Não se trata de afirmar que há intencionalidade em toda e qualquer configuração da res extensa, apenas defende-se que não existe uma ruptura qualitativa no surgimento de tais propriedades. Como diz Merleau-Ponty, "é natureza o que tem um sentido, sem que esse sentido tenha sido estabelecido pelo pensamento. É a autoprodução de um sentido." (idem, p. 4), ou seja, há somente uma gradual sequência de organizações de entes que possibilitam diferentes manifestações do mesmo princípio: “o que se denomina de Eu e o que se denomina de ser vivente têm uma raiz comum no Ser préobjetivo" (idem, p. 64). Desse modo, “não se deve então colocar almas nas próprias coisas, ou espécies de almas, 'análogos de alma', como diria Leibniz” (idem, p. 67). $\mathrm{Na}$ verdade, deve-se meramente atestar que o fundamento ontológico do tipo de intencionalidade que há no Para-si igualmente percorre o restante do Ser. Voltando ao exemplo acima de Merleau-Ponty acerca do cachorro e do enxofre, nota-se que a esfera reflexiva do Eu facilmente é capaz de perceber, dividir e categorizar inúmeras diferenças que marcam cada ente; porém, tanto o primeiro quanto o segundo são 
ocorrências de uma propriedade incrustada no Ser que é anterior a qualquer tese proposicional, sendo aquilo mesmo que a fundamenta e, por isso, apreensível somente de modo indireto, nunca em sua face derradeira, pois a physis é "o primordial, ou seja, o não-construído, o não-instituído" (idem, p. 4).

Poder-se-ia falar, a propósito de Schelling, de uma prioridade da existência sobre a essência. Essa erste Natur é o elemento mais antigo, um "abismo de passado" que sempre fica presente em nós como em todas as coisas. Essa erst Natur é "o tecido fundamental de toda vida e de todo existente, algo de assustador, um princípio bárbaro [erste Natur] que se pode superar, mas jamais deixar de lado" [Schelling]. Trata-se de um esforço para explicar esse pré-ser que, tão logo chegamos, já está ali. Esse excesso do Ser sobre a consciência do Ser, eis o que Schelling quer pensar com todo rigor (Merleau-Ponty, 2006a, pp. 60-61).

Como pensar essa natureza primordial, esse excesso do Ser? Como tentar vislumbrar o Ser Bruto ou o Princípio Bárbaro? Ambos (assim como Leibniz, MerleauPonty ressalta) encontram na percepção a mesma via investigativa inicial: "Schelling não quer recorrer a uma faculdade mística, especializada nesse papel. O que Schelling quer dizer é que se redescobre a Natureza em nossa experiência perceptiva antes da reflexão" (Merleau-Ponty, 2006a, p. 63). Com isso, do mesmo modo que Merleau-Ponty descreve a percepção pré-reflexiva formadora de Gestalten do Corpo Próprio como o momento não-representacional de contato com o Ser (fazendo da intencionalidade motriz o centro irradiador de sentido), Schelling defende a percepção como janela de desvelamento do fundamento originário do Absoluto: "para reencontrar o sentido da natureza exterior, cumpre fazer um esforço a fim de reencontrar a nossa própria natureza no estado de indivisão em que exercemos a nossa percepção” (idem, ibidem). Essa descrição da indivisão sujeito-objeto que ocorre na esfera pré-reflexiva de apreensão do Ser (igualmente efetuada por Schelling) serve para Merleau-Ponty propor que "a percepção é um quiasma no interior da sensibilidade" (Ramos, 2013, p. 159, grifo da autora). É aqui, segundo o fenomenólogo francês, que reside o erro de Gottlieb Fichte, pois o sistema do alemão parte da consciência como régua para as diversas instâncias de subjetividade, enquanto que Schelling - para usarmos a terminologia merleau-pontiana - compreende que a physis já é Carne, o todo já está carregado da negatividade que, enraizada no Ser, transborda no Para-si.

As noções de Carne e Princípio Bárbaro expressam a unidade qualitativa das diversas ocorrências de entes, auxiliando Merleau-Ponty a defender uma reversibilidade do tecido do Ser e o caráter indivisível da natureza, indicando um estofo comum. Com isso, uma redução fenomenológica procedida corretamente não serve apenas na elucidação da noese e noema, mas no desvelamento do solo originário no qual pulsa a negatividade que perpassa a totalidade (cf. KahlmeyerMertens, 2016). É com isso em mente que Merleau-Ponty não vê dificuldade em se aproximar de Schelling. 
Schelling censura Fichte por procurar o modelo único de toda subjetividade na consciência, e por acreditar que toda aparência de subjetividade é derivada daquela. A filosofia de Fichte não enxerga outro interior senão a consciência humana. Para Schelling, ao contrário, toda coisa é Eu. Daí o papel do mundo percebido como ambiente de experiência em que não há projeção da consciência sobre todas as coisas, mas participação da minha própria vida em todas as coisas, e reciprocamente. O que Schelling descobre aqui é aquilo que Leibniz já tinha sugerido: a percepção nos ensina uma ontologia que ela é a única a poder nos revelar. Daí o esforço de Leibniz para nos apresentar o mundo percebido como um mundo original, e o papel da noção de perspectiva, de geometral, de relação de expressão (Merleau-Ponty, 2006a, p. 64).

Quando Chauí (2002) afirma que Merleau-Ponty vai da fenomenologia à ontologia, tal caracterização está correta; entretanto, ao apontar o objetivo de Schelling, Merleau-Ponty acaba por também definir (de modo mais preciso, a nosso ver) sua própria obra tardia: “Ele [Schelling] quer atingir o 'não-sabido', o Unbewusste, não uma ciência da Natureza, mas uma fenomenologia do Ser préreflexivo" (Merleau-Ponty, 2006a, p. 66, grifo nosso). A ontologia tardia, portanto, pode ser definida como sinônimo de Fenomenologia do Ser Pré-Reflexivo e, com isso, novamente lembramos que se pode afirmar aqui uma continuidade temática na obra do francês. ${ }^{2}$

A percepção nos revela o caráter de "uma espécie de indivisão" (idem) subjacente à totalidade, ao Absoluto. Seja na descrição fenomenológica do Corpo Próprio ou do pós-impressionismo de Cézanne (Merleau-Ponty, 2004), Merleau-Ponty se esforça em expor o caráter pré-reflexivo da percepção como abertura ao Ser, pois é justamente na gestação da Gestalt que se torna mais evidente a imbricação homem-natureza. Como Ramos afirma, assumir a indivisibilidade do Ser, em última instância, significa notar que "a reflexão, assim como a percepção, possa ser compreendida como algo que emerge no interior do próprio ser" (Ramos, 2013, p. 143, grifo da autora). Ora, postular essa unicidade por meio do exame da percepção claramente remete à Naturphilosophie de Schelling e, assim como Merleau-Ponty, o filósofo alemão vê na arte em geral um meio de desvelamento do Princípio Bárbaro (cf. Schelling, 2010). Por ser atividade criativa relacionada ao Unbewusste, a arte possui lugar de destaque na tarefa de ensejar a apreensão do solo originário. Porém, a arte, as ciências e a análise da percepção não são as únicas esferas que servem para enriquecer o projeto de uma ontologia indireta. Até mesmo experiências de cunho religioso podem jogar luz na reflexão sobre o indeterminado da multiplicidade

\footnotetext{
2 É o que faz Moutinho (2006, pp. 23-27) em Razão e Experiência: "O tema deste livro é a ontologia indireta de Merleau-Ponty - ontologia que define, do começo ao fim, o projeto filosófico de nosso autor. [...] Em uma nota de trabalho de O Visível e o Invisível, datada de fevereiro de 1959, Merleau-Ponty faz um comentário genérico sobre a Fenomenologia da Percepção, de 1945: ainda que a tenham considerado uma obra de psicologia, ela é, na realidade, uma ontologia (VI, 230). A Fenomenologia..., apesar de ter por objeto a percepção, não se alinharia aos livros que, como 0 Imaginário de Sartre, pretendem ser um exercício de 'psicologia fenomenológica'. Não, ela é um manual de ontologia".
} 
temporal constituinte do Ser. A filosofia, contudo, permanece como campo autônomo e necessário à caracterização do Absoluto.

A arte atinge o Absoluto porque num dado momento o consciente atinge 0 inconsciente: esta ideia está em germe na Crítica do Juízo, na qual Kant mostra que "o entendimento está a serviço da imaginação" e sugere que a arte consiste na reconciliação da passividade e da atividade [...] A arte é essa experiência da identidade do sujeito e do objeto. Não se sabe mais o que é fato e o que é ideia: tudo se liga numa produção. [...] A filosofia não se sublima na arte. Existe simplesmente uma relação possível entre a experiência do artista e a experiência do filósofo, a saber, que a experiência do artista é aberta, é uma ek-stase. Em suma, Schelling não crê que a filosofia deva esperar tudo de si mesma e não confiar em nenhuma outra experiência, religiosa ou artística. [...] 0 acesso ao Absoluto pela filosofia não é, portanto, exclusivo (Merleau-Ponty, 2006a, pp. 74-75).

Além da arte, da religião e da filosofia como vias de acesso ao Ser, deve-se ressaltar a importância do fenômeno da Stiftung que Merleau-Ponty pensa a partir da linguística de Saussure (cf. Chauí, 2012). Ela funciona como mais uma janela na qual podemos compreender que a formação da Gestalt não é unilateral: "a instituição [Stiftung] não é um ato de um sujeito, não é um sentido doado ou constituído pela consciência” (Ramos, 2013, p. 178). Não há uma totalidade desprovida de sentido ou expressividade, pois, como Schelling argumenta, há uma identidade entre o Eu e o Absoluto que implica na existência de uma negatividade da physis, isto é, "Schelling apresenta o aparecimento do homem como uma espécie de recriação do mundo, como o advento de uma abertura" (Merleau-Ponty, 2006a, p. 77). A consciência é abertura ao Ser pelo próprio Ser. A Stiftung, portanto, denota essa ideia que aponta para o irrompimento do sentido no seio da própria natureza, indicando que a valoração originária precede a intencionalidade de ato husserliana: "É preciso que haja nas coisas uma preparação daquilo que vai ser em seguida sentido explícito" (idem, p. 69). Ela também serve para dispensar a noção de organismos individuais isolados, pois, tanto no animal quanto no homem, a Stiftung é subjacente às “condutas partilháveis no interior de uma espécie” (Ramos, 2013, p. 178). Em outras palavras, há experiências comuns aos organismos particulares de uma espécie que possibilitam o estabelecimento de um Umwelt (cf. Uexküll, 2006), ou seja, padrões normativos compartilhados que identificam, no caso humano, o vermelho, o doce, o azedo ou qualquer outro quale que se queira. A importância disso para a presente discussão ontológica diz respeito ao modo que, por exemplo, a vermelhidão surge à percepção humana. A percepção que normatiza fatos recorrentes do mundo funciona como a linguagem e é isso, em poucas palavras, que define "o principal ensinamento legado por Saussure", a saber, a tese na qual "A língua forma um todo cujas partes não podem ter seu campo semântico fixado de maneira isolada, pois o sentido de cada parte depende da relação opositiva estabelecida com os termos que the são próximos” (Ramos, 2013, p. 182). Ora, o mesmo se dá no plano perceptivo. Cada quale 
(vermelhidão, brancura, etc.) é percebido dentro de uma teia de outras ocorrências que, relacionadas, proporcionam a significação de cada uma, ou seja, um vermelho específico que enxergamos é "menos cor ou coisa do que diferença entre as coisas e as cores, cristalização momentânea do ser colorido ou da visibilidade" (MerleauPonty, 2009, p. 129). Dito de outro modo, "o que aprendemos com Saussure é que os signos um a um não significam nada, que cada um entre eles menos exprime um sentido do que marca um desvio de sentido entre ele mesmo e os outros" (MerleauPonty, 2003, p. 49). A linguagem é a casa ou morada do Ser, diria Heidegger (2003). Em suma, há uma conexão entre os entes que revela a imbricação carnal originária como solo fundacional do sentido apreendido pela percepção, já que "este vermelho é o que é ligando-se, do seu lugar, com outros vermelhos em volta dele, com os quais forma uma constelação [...]. É uma concreção da visibilidade, não um átomo" (Merleau-Ponty, 2009, p. 129).

A discussão da linguagem como fenômeno análogo à percepção, como se vê, é mais um ponto que permite reafirmar a relevância da filosofia de Schelling na obra de Merleau-Ponty (cf. Suzuki, 2003). A esfera pré-reflexiva da percepção não se prende a partes discriminadas pré-configuradas do entorno do organismo, ela funciona como apreensão ou irrompimento de conjuntos significativos. Como diz Moutinho (2006, p. 299), "A percepção não é a soma de elementos que correspondem, um a um, a eventos externos, tal como a língua não é a soma de termos elementares que designam, um a um, coisas e ideias.”; há sempre uma Gestalt em formação a cada instante da existência que vem à tona por meio do campo perceptivo de relações opositivas que, por sua vez, independem (até certa medida) do olhar humano, pois a natureza já contém a estrutura oposicional do sentido característica da linguagem. A ontologia tardia de Merleau-Ponty, com isso, utiliza o pensamento de Saussure para apontar que "há uma linguagem da natureza [...] a linguagem opera do mesmo modo que a natureza" (Ramos, 2013, p. 187, grifo da autora). Ora, se a linguagem opera como a natureza e a percepção opera como a linguagem, logo, a natureza opera como a percepção. Ela é sensível e, com isso, vidente e visível, ou seja, "o mundo é a carne universal" (Merleau-Ponty, 2009, p. 134). É isso que aproxima Schelling de Merleau-Ponty: ambos apontam para uma natureza que já opera em regime de negatividade, evitando assim a necessidade da postulação de um salto qualitativo (impossível aos olhos de Schelling e Merleau-Ponty) que faria o Eu surgir da pura imobilidade e positividade. 0 exame da percepção nos revela que "Não há, portanto, coisas idênticas a si mesmas, que, em seguida, se oferecem a quem vê" (idem, p. 128).

Outro uso da percepção como meio de descortinamento do Ser é o exemplo da apreensão fenomenológica da luz, algo que ilustra a ambiguidade e o entrelaçamento entre os diversos entes. Quando vejo uma mesa por conta da luminosidade, há aqui 
um enlace que permite o vislumbre da unidade na multiplicidade. 0 evento que constitui a percepção de um ente é, no fundo, “carne aplicada a outra carne” (idem, ibidem).

Assim, a luz pode ser considerada matéria; mas a luz é também outra coisa, ela é sutil, penetra por toda a parte, explora o campo promovido pelo nosso olhar e o prepara para ser lido. A luz é uma espécie de conceito que passeia nas aparências; não tem existência subjetiva, salvo quando se torna para nós. A luz não conhece o mundo, mas eu vejo o mundo graças à luz. Não se pode considerar seu poder penetrante como se não fosse nada. Há três gêneros de seres ilustrados pela mesa, a luz e o Eu. Recusar este terceiro sentido do Ser é fazer desaparecer toda relação carnal com a Natureza (Merleau-Ponty, 2006a, p. 69).

O Eu não está destacado do ser-natural ou de entes onde, organizacionalmente, prepondera elementos de passividade e imobilidade. Há um aspecto sujeito-objeto ou visível-vidente em toda existência, pois toda manifestação do Ser é carregada de um Princípio Bárbaro que possibilita a construção da noção de Identität proposta por Schelling durante os anos de 1801 e 1806 onde há um aprofundamento da Naturphilosophie. Com isso, percebe-se que a ontologia de Merleau-Ponty é óbvia devedora de Schellin; a reversibilidade do ser-carnal merleau-pontiano se apoia na perspectiva do filósofo alemão na qual a natureza é revestida com a negatividade e a expressividade fundantes do Eu. Schelling nega o sistema de Fichte e se empenha em reintegrar as características constituintes do sujeito ao próprio Absoluto: “a própria natureza é definida por Merleau-Ponty, segundo a perspectiva schellinguiana, como 'sujeito-objeto puro', quer dizer, como uma existência que não pode ser compreendida somente como atividade - ou como naturante puro - mas sim como atividade $e$ passividade" (Ramos, 2013, p. 158, grifo da autora). A negatividade característica do Para-si não é somente fim, mas igualmente começo e meio da totalidade do logos. A continuidade de expressividade simbólica entre physis e homem (vislumbrada na pré-reflexividade perceptiva e, segundo Merleau-Ponty, também corroborada pela ciência) é a conceitualização de natureza que há, mutatis mutandis, na filosofia de Schelling: "somos os pais de uma Natureza de que somos os filhos. [...] o homem é a Mitwisserschaft da Criação; ele é o portador dos traços de tudo aquilo que a Natureza foi, é a recapitulação e o contemporâneo da Criação" (Merleau-Ponty, 2006a, p. 70). Com isso em mente, compreende-se como Schelling se afasta outrossim de Kant, pois sua concepção nega a autonomia pura da vontade kantiana que, de certo modo, catapulta o homem do encadeamento físico do sistema da natureza dos modernos um pressuposto para que a moral do fundador do idealismo alemão não desmorone (cf. Lebrun, 2002): "Schelling junta-se aqui aos pensadores da Renascença, como [Giordano] Bruno, para quem o homem é um microcosmo, um homem pleno e não, como em Kant, uma liberdade vazia, uma antiphysis" (idem, pp. 70-71). Desse modo, fica clara a fundamentação da Identitätsphilosophie de Schelling na qual o 
pensar e o existir são tomados como caracteres indissociáveis (cf. Schelling, 1973); daí a possibilidade de compreensão do Ser pelo exame da abertura perceptiva do Fürsichsein ou, como diria Heidegger, do desvelamento ininterrupto que define o caráter de imbricamento não-representacional do Dasein (cf. Heidegger, 2006).

Nessa auto exposição do Absoluto, diz Schelling, ele se manifesta como identidade absoluta, isto é, como absoluta unidade e identidade consigo mesmo, cuja fórmula mais geral pode ser expressa pela proposição $A=A$. Ora, se a razão é o próprio Absoluto, não pode haver nada fora dela, de modo que tudo deve ser nela. Assim, a lei da identidade $(A=A)$ vale para todo ser, na medida em que ele é considerado tal como é em si, no Absoluto. Essa proposição, $\mathrm{A}=\mathrm{A}$, é o único conhecimento incondicionado, uma vez que é o único a exprimir a essência da razão (Nogueira, 2019, p. 186).

Se a razão (logos) é o próprio Ser, oAbsoluto necessariamente há de se manifestar no processo de gestação perceptiva do Eu que, pela sua negatividade intrínseca, nos impele à caracterização que assume uma unicidade e uma historicidade do todo. Desse modo, partindo da tese de Identität de Schelling, resta apenas "conceber algo como uma temporalização do Absoluto" (Nogueira, 2019, p. 200, grifo do autor). Seguindo Schelling, Merleau-Ponty trata de assumir semelhante postura em sua ontologia: "há um tempo inerente à Natureza. [...] A subjetividade está presa na engrenagem de um tempo cósmico, numa subjetividade da Natureza" (Merleau-Ponty, 2006a, pp. 194-195). A temporalização do Absoluto é uma consequência lógica do princípio de identidade de Schelling, algo assumido por Merleau-Ponty e convergente com sua leitura da mecânica quântica e do conceito de natureza postulado por Whitehead (1995). Não há mais evidências que corroborem uma cisão entre ser-natural-unoimóvel de um lado e ser-histórico-múltiplo-finito de outro. 0 desenvolvimento das ciências naturais e também da linguística, argumenta Merleau-Ponty, serve como demonstrativo indireto do caráter temporal do Ser. Deve haver uma negatividade já no próprio âmago da physis, obrigando-nos a reconhecer-lhe produtividade, expressividade e temporalidade. Portanto, para Merleau-Ponty, é condição sine qua non assumir que “uma verdadeira ontologia requer que o tempo seja ‘devolvido' ao coração do ser, isto é, que a temporalidade seja readmitida na imanência mesma da natureza, juntamente com os aspectos de ‘negação' e 'produtividade’” (Mousinho, 2009, p. 84).

Do mesmo modo que Whitehead (2006) chama seu projeto ontológico de Filosofia do Organismo, pode-se afirmar que "tanto em Schelling quanto em MerleauPonty, encontramos um mesmo esforço teórico de pensar uma vida do Absoluto" (Nogueira, 2019, p. 212, grifo do autor), o que nos leva - a seguir - à noção merleaupontiana de Carne, conceito que exprime o fundamento da reversibilidade que revela - Quiasma do Ser e reitera sua proximidade com Schelling ao revestir o Absoluto de sensibilidade e temporalidade: “há um tempo cósmico inscrito na natureza, de 
modo que não faz sentido pensar que a temporalidade nasce com o espírito ou a consciência" (Ramos, 2013, p. 175).

II.

Em $O$ visível e o invisível, Merleau-Ponty se indaga: "onde colocar o limite do corpo e do mundo, já que o mundo é carne?” (Merleau-Ponty, 2009, p. 134). Essa postura claramente reverbera o pensamento de Schelling, indicando que a ontologia do $\hat{E}$ tre Brut pode ser compreendida como um empreendimento análogo ao do idealista alemão: "a filosofia de Schelling procura restituir uma espécie de indivisão entre nós e a Natureza considerada como um organismo, indivisão condicionada pela indivisão sujeito-objeto" (Merleau-Ponty, 2006a, p. 76). O próprio Schelling se expressa de modo a confirmar a apropriação merleau-pontiana posterior, como quando o alemão diz que, afinal de contas, a "Natureza é apenas espírito visível" (Schelling, 2004, p. 132, grifo do autor). Merleau-Ponty assume que há um erro categórico em distinções de tipo sujeito-objeto, matéria-vida ou natureza-cultura, pois tudo que é physis possui um caráter de reversibilidade vidente-visível, revelando assim a expressividade de uma mesma propriedade impregnada no Ser (estabelecendo uma diferença entre os entes em termos de grau e não qualidade). Ora, o que encontramos, então, nas obras A Estrutura do Comportamento e A Fenomenologia da Percepção? Há nelas alguma defesa de descontinuidade entre a existência humana e as demais composições da natureza? De acordo com Ramos, "a transformação do organismo em corpo próprio o surgimento da estrutura coisa - é fundamental porque é o índice de ruptura entre a ordem biológica e a ordem antropológica" (Ramos, 2013, p. 61, grifo nosso). É exatamente esse vestígio de ruptura que, posteriormente, Merleau-Ponty admite e visa corrigir. Deve-se repensar a ideia de cogito tácito que, ao fim e ao cabo, revelouse insuficiente como ultrapassagem do cartesianismo (cf. Moutinho, 2012). A matéria, independentemente de sua configuração específica, é inerentemente carnal, já que é feita do mesmo estofo, isto é, erste Natur: essa é a radicalização que marca a ontologia indireta apresentada na década de 1950. A partir do detalhado exame dos novos paradigmas estabelecidos nas ciências naturais - além do aporte conceitual retirado, entre outros, de Whitehead e Schelling - Merleau-Ponty se encontra capaz de pensar um conceito de natureza em que o tecido da existência apresenta uma reversibilidade carnal comum a todos os entes. Não há aqui uma recaída vitalista, mas uma reconfiguração conceitual que pretende entrar em harmonia com a visão contemporânea de uma natureza pós-newtoniana.

A caracterização do ser como inerentemente sensível é uma tese filosófica pela qual Merleau-Ponty pretende superar a cisão entre sujeito e objeto em que a Fenomenologia da Percepção teria ficado presa. Segundo sua ontologia final, o ser sensível contém 
as condições da sensibilidade posteriormente exercida pelo sujeito perceptivo. [...] Merleau-Ponty elabora a tese da sensibilidade inerente ao ser por meio da noção de carne (Sacrini, 2008, p. 225).

Pensar em uma Carne do Ser, ou melhor, conceitualizar o Ser como dotado de Carne, isto é, de uma sensibilidade intrínseca, é notar a indivisão primordial revelada pela camada pré-reflexiva que brota da negatividade do Para-si de que tratamos na seção anterior; é também compreender a indistinção originária a partir do Eu, pois o Ser aporta na intencionalidade e possibilita entrever o caráter de Quiasma da physis. Nos termos de Schelling, quer dizer que devemos

reencontrar num nível superior aquilo que foi vivido organicamente, passar da prédialética a uma metadialética, passar daquilo que Schelling chama de filosofia negativa, que é o sentimento dialético dessa separação entre a reflexão e o nãosabido, para o que ele designa como filosofia positiva (Merleau-Ponty, 2006a, p. 76).

Trata-se da abertura ao Ser pelo próprio Ser encarnado no ente-homem, isto é, "Schelling apresenta o aparecimento do homem como uma espécie de recriação do mundo, como o advento de uma abertura" (idem, p. 77). Esta abertura, como dito acima, é patente, acima de tudo, na instância pré-reflexiva da percepção (janela para o Ser, desvelamento do Princípio Bárbaro), algo que aproxima Schelling não só de Leibniz e Merleau-Ponty (como já elucidamos), mas também de Bergson, o que, em um primeiro momento, pode parecer clara incidência de erro, como o próprio Merleau-Ponty admite: “à primeira vista, nada há de comum entre as teses bergsonianas e as de Schelling" (idem, p. 84); no entanto, ambos assumem o papel cabal da percepção como desvelamento da unicidade do Absoluto.

A filosofia de Bergson é aparentada com a de Schelling porque Bergson inteiro está na ideia de uma unidade como algo que é óbvio e primordial. Assim, Bergson admite na origem uma unidade das espécies, a unidade do vegetal e do animal; unidade nativa, primordial, desfeita e expressa naquilo que vem em seguida, e em relação à qual a ideia de nada não tem nenhum sentido. O Ser é aquilo que é primordialmente constatado, aquilo em relação ao qual todo recuo é impossível. A unidade é dada mais no ponto de partida que no desenvolvimento. Da mesma forma, a percepção abre-nos para as próprias coisas e revela-nos uma ordem primordial, a qual é um horizonte que nunca podemos eleger como domicílio do nosso pensamento, embora permaneça sempre como obsessão deste último (Merleau-Ponty, 2006, p. 86).

É justamente a sua versão da unicidade do Ser - defendida por Bergson e Schelling (cada um a seu modo) - que Merleau-Ponty traz à tona com o conceito de Carne. Segundo o fenomenólogo, é um equívoco em ontologia - diante do acúmulo de dados do paradigma científico vigente - pressupor uma fissura ou cisão qualitativa entre as diversas ordenações da physis. Tal ruptura é logicamente inaceitável, pois vai na contramão da paisagem científica contemporânea marcada por constatações como a dualidade onda-partícula e o colapso da função de onda (cf. Norsen, 2017) 
que refazem a imagem da natureza preconizada pela modernidade: "o pensamento moderno culmina com a ideia de que a natureza é um objeto pleno e sem interioridade" (Ramos, 2013, p. 15). Por conta disso, a percepção de um ente visível como, e.g., uma cor deve ser reavaliada para entrar em harmonia com essa nova noção, digamos, menos sólida ou mais maleável da matéria e da natureza, pois "uma cor nua e, em geral, um visível, não é um pedaço de ser absolutamente duro, indivisível, oferecido inteiramente nu a uma visão que só poderia ser total ou nula" (Merleau-Ponty, 2009, p. 129). 0 caráter aberto da camada pré-objetiva da corporeidade humana é associado agora ao próprio tecido do Ser e, desse modo, "a nova ontologia de Merleau-Ponty assume como tarefa a compreensão de uma natureza dotada de interioridade e em si mesma expressiva" (Ramos, 2013, p. 152). Trata-se de, enfim, alastrar a expressividade do Corpo Próprio para a totalidade do Ser, pois, de acordo com Merleau-Ponty, a ciência do século XX oferece-nos uma imagem da natureza onde a res extensa dotada de positividade e imobilidade parece não ter vez, o que, a seu ver, "exige afirmar que a percepção e a expressão não são privilégios humanos, como em $A$ Estrutura do Comportamento" (idem, p. 200). A natureza inteiramente decomponível, calculável e preditiva de Laplace torna-se obsoleta, ao passo que concepções dialéticas como as de Schelling se mostram mais aptas a estabelecer uma ontologia em harmonia com a física contemporânea: "não há, portanto, coisas idênticas a si mesmas, que, em seguida se oferecem a quem vê" (Merleau-Ponty, 2009, p. 128). Em outras palavras, "a mecânica quântica e a teoria da relatividade oferecem uma série de formulações que colocam em xeque os aspectos da ciência clássica" (Ramos, 2013, p. 168). 0 vidente e o visível, para usarmos a terminologia merleau-pontiana, expressam o Quiasma que fundamenta o Ser, impossibilitando uma imagem de natureza tomada como plena e imóvel, sem espaço para a negatividade de tipo schellinguiana. Deve haver, Merleau-Ponty argumenta, uma espécie de elemento qualitativo que perpassa a totalidade e possibilita o refinamento da negatividade como um processo gradual e não disruptivo. O Ser, portanto, deve ser tomado como um todo carnal, um todo que já é sensibilidade e organicidade, isto é, um campo de possibilidade aberto que se percebe até mesmo no nível subatômico. Há uma Identität originária, diria Schelling. Com isso em mente, pode-se conjecturar que Merleau-Ponty diria que o logos não poderia se fazer carne como em João 1:14, pois o logos já é Carne; não há espaço aqui para o dualismo característico do monoteísmo abraâmico. Além disso, a Carne é um conceito que, como o próprio Merleau-Ponty ressalta abaixo, deve ser compreendido no sentido pré-socrático de Arché.

A carne não é matéria, não é espírito, não é substância. Seria preciso, para designá-la, o velho termo "elemento", no sentido em que era empregado para falar-se da água, do ar, da terra e do fogo, isto é, no sentido de uma coisa geral, meio caminho entre o indivíduo espacio-temporal e a ideia, espécie de princípio encarnado que importa um estilo de ser em todos os lugares onde se encontra uma parcela sua. Neste sentido, a 
carne é um "elemento" do Ser. Não fato ou soma de fatos e, no entanto, aderência ao lugar e ao agora. Ainda mais: inauguração do onde e do quando, possibilidade e exigência do fato, numa palavra, facticidade, o que faz com que o fato seja fato (Merleau-Ponty, 2009, p. 136, grifos do autor).

Com a noção de Carne, Merleau-Ponty sintetiza sua ontologia do Être Brut, ela possui o poder de expressar a unicidade da physis e a reversibilidade ou Quiasma do Ser. Assim como é observado no Princípio Bárbaro de Schelling, o fenomenólogo defende a impossibilidade de um salto da pura positividade à negatividade percebida no Eu e no fenômeno da vida como um todo. Deve haver, Merleau-Ponty argumenta, uma continuidade gradativa que conecta a totalidade do Ser, tornando-o um tecido carnal, sensível e unitário. A vida, a cultura e a consciência devem ser concebidas dentro de uma reversibilidade presente na inteireza do cosmos. O fenômeno da consciência humana, é claro, precisa ser compreendido em sua peculiaridade e dentro da historicidade do Ser, mas seu fundamento é perene, já perpassa os entes sem por eles ser confundido.

A carne não é matéria, no sentido de corpúsculos de ser que se adicionariam ou se continuariam para formar os seres. O visível (as coisas como meu corpo) também não é não sei que material "psíquico" que seria, só Deus sabe como, levado ao ser por coisas que existem como fato e agem sobre meu corpo de fato. De modo geral, ele não é fato nem soma de fatos "materiais" ou "espirituais". Não é, tampouco, representação para um espírito: um espírito não poderia ser captado por suas representações, recusaria essa inserção no visível que é essencial para o vidente (Merleau-Ponty, 2009, pp. 135-136).

A Carne é precursora da pré-reflexividade do Corpo Próprio. Na Fenomenologia da Percepção, a motricidade humana é compreendida como uma intencionalidade operante "responsável por quebrar a plenitude da natureza" (Ramos, 2013, p. 142); trata-se agora de defender univocamente que "o movimento pelo qual o Ser se faz consciência e história tem sua fonte no polimorfismo do Ser selvagem e pré-objetivo" (Dastur, 2001, p. 128). É isso que marca o distanciamento que Merleau-Ponty opera em relação às obras da década de 1940 e define sua aproximação com a filosofia de Schelling. A esfera simbólica humana não está destacada do Princípio Bárbaro, isto é, toda manifestação do Ser está dotada de Carne.

A Estrutura do Comportamento concebia a natureza como relacional ao admitir que o todo antecede as partes. Também a Fenomenologia da Percepção combatia a ideia de sensações, segundo a qual a natureza é um composto de partes não ligadas. Mas, insistimos, o que está em jogo aqui é um outro problema: como pensar a natureza de modo que não esteja subordinada às categorias humanas, de modo que ela não seja, como pondera o curso sobre a instituição [Stiftung], uma “projeção" do sujeito? Como pensar uma natureza cuja produtividade não se deva ao ponto de vista humano? Para Merleau-Ponty, só há um caminho possível: pensar a técnica, a filosofia, as artes, as idealidades, a história, enfim, as instituições humanas como desdobramentos da expressividade natural; mostrar que a natureza é o berço da expressão - e não o homem, o cogito, ou o nada (Ramos, 2013, pp. 200-201) 
O domínio simbólico presente à consciência humana, na verdade, provém do interior do Ser. Não é a negatividade do Para-Si que instaura ou projeta a multiplicidade das variadas expressões daquilo que chamamos de esfera cultural ou simbólica, pois agora o próprio ser-natural comporta tal expressividade. Desse modo, resta assumir essa ontologia e alinhar-se à Schelling no sentido de defender que "não é o homem quem inaugura a ordem do simbólico, pois, na verdade, o sujeito continua uma produtividade que acontece originariamente no interior da carne compreendida de maneira ontológica" (idem, p. 148). Com isso, a propriedade que possibilita o irrompimento da consciência e da esfera simbólica, para usarmos a terminologia de Schelling, é parte constituinte do Unbedingte, isto é, o solo originário, o incondicionado. Assim como no conceito merleau-pontiano de Carne, a filosofia da natureza de Schelling parte do princípio de que todo ente é, no fundo, uma manifestação particular do uno, ou seja, o Princípio Bárbaro é o elemento que perpassa tudo aquilo que jorra do Unbedingte. Certamente poderíamos elencar os pormenores que afastam Schelling de Merleau-Ponty, mas a citação abaixo da obra Erster Entwurf eines Systems der Naturphilosophie de 1799 torna evidente o porquê do fenomenólogo ter encontrado no alemão uma inspiração crucial para sua ontologia tardia.

O incondicionado [Unbedingte] não pode ser buscado em nenhuma "coisa" individual, nem em nada que se possa dizer que "é". Pois o que "é" apenas participa do ser, $e$ é tão somente uma forma ou tipo individual de existência. - Inversamente, nunca se pode dizer do incondicionado [Unbedingte] que ele "é". Pois ele é o SER COMO TAL, $e$ assim, ele não se exibe em nenhum produto finito, e todo particular, por assim dizer, é uma manifestação específica dele (Schelling, 2004, p. 13, grifo do autor).

A temporalização do Absoluto e a Identität entre o Eu e o Unbedingte demonstram que a ontologia indireta de Merleau-Ponty é devedora da Naturphilosophie de Schelling. A unidade da existência não significa que todo particular seja idêntico, tampouco que todo ente manifeste uma condição de possibilidades existenciais equivalente à intencionalidade presente no homem. O Ser uno, seja como Carne ou como erste Natur, aponta para uma ontologia entre o Ser e o Nada (cf. Moura, 2010), ou seja, não há pura imobilidade, nem pura negatividade, mas uma imbricação de expressividade e produtividade contínua do Unbedingte.

\section{Conclusão}

Friedrich Schelling é, inegavelmente, um dos pilares constitutivos da ontologia indireta merleau-pontiana da década de 1950. Percebe-se, nos Cursos do Collège de France e no manuscrito $O$ visível e o invisível, um refinamento de sua perspectiva ontológica no qual a noção de erste Natur de Schelling encontra clara reverberação. Diversos são os pontos de distanciamento entre os filósofos que podem ilustrar as 
diferenças em suas respectivas noções de natureza, porém, o intuito aqui foi apontar - assim como Merleau-Ponty - os pontos de contato, os quais indicam a constante relevância do idealismo alemão na filosofia contemporânea.

\section{Referências}

Bimbenet, E. (2004). Nature et Humanité: Le problème anthropologique dans l'ouvre de Merleau-Ponty. Paris: Librarie Philosophique J. Vrin.

Chauí, M. (2002). Experiência do Pensamento: Ensaios sobre a obra de MerleauPonty. São Paulo: Martins Fontes.

Chauí, M. (2012). Merleau-Ponty: da constituição à instituição. Revista Dois Pontos, 9(1), 155-180. DOI: http://dx.doi.org/10.5380/dp.v9i1.29097

Dastur, F. (2001). Chair et langage: essais sur Merleau-Ponty. La Versane Encre Marine.

Heidegger, M. (2003). A caminho da linguagem. Tradução de Márcia Sá Cavalcante Schuback. Petrópolis, RJ: Vozes; Bragança Paulista, SP: Editora Universitária São Francisco.

Heidegger, M. (2006). Ser e Tempo. São Paulo: Editora Vozes

James, W. (1988). A Pluralistic Universe. In: William James: Writings 1902-1910. New York: Library of America.

Kahlmeyer-Mertens, R. S. (2016). “Redução Fenomenológica enquanto retorno ao Mundo-da-Vida”. In: Merleau-Ponty - Compêndio. São Paulo: Ed. LiberArs.

Kant, I. (1987). Critique of Judgement. Indiana: Hackett Publishing Company.

Lebrun, G. (2002). Kant e o fim da metafísica. São Paulo: Martins Fontes.

Merleau-Ponty, M. (1942). La structure du comportement. Paris: PUF.

Merleau-Ponty, M. (1945). Phénoménologie de la perception. Paris: Gallimard.

Merleau-Ponty, M. (1964). Le visible et l'invisible. Paris: Galimard.

Merleau-Ponty, M. (1968). Résumés de Cours. Collège de France (1952-1960), Paris: Gallimard.

Merleau-Ponty, M. (1999). Fenomenologia da Percepção. Tradução C. A. de Ribeiro de Moura. São Paulo: Martins Fontes.

Merleau-Ponty, M. (2003). Signes. Paris: Gallimard.

Merleau-Ponty, M. (2004). “A Dúvida de Cézanne”. In: O Olho e o Espírito. Trad. Paulo Neves e Maria E. Galvão Gomes Pereira. São Paulo: Cosac \& Naify.

Merleau-Ponty, M. (2006a). A Natureza: Curso do Collège de France. 2 ed. Tradução de Álvaro Cabral. São Paulo: Martins Fontes. 
Merleau-Ponty, M. (2006b). A Estrutura do Comportamento. Tradução de M. V. M. de Aguiar. São Paulo: Martins Fontes.

Merleau-Ponty, M. (2009). O visível e o invisível. 4. ed. Tradução de José Arthur Giannotti e Armando Mora d'Oliveira. São Paulo: Perspectiva

Moura, A. C. (2010). Entre o Ser e o Nada: a dissolução ontológica na filosofia de Merleau-Ponty. Tese de Doutorado em Filosofia - Faculdade de Filosofia, Letras e Ciências Humanas, USP. São Paulo.

Mousinho, P. (2009). Natureza, tempo e movimento: Merleau-Ponty leitor de Whitehead. O que nos faz pensar: Cadernos do Departamento de Filosofia da PUC-Rio, 25, 79-94

Moutinho, L. D. S. (2006). Razão e experiência: ensaio sobre Merleau-Ponty. São Paulo: Ed. Unesp.

Moutinho, L. D. S. (2012). Merleau-Ponty e a "filosofia da consciência". Revista Dois Pontos, 9(1), 121-153. Curitiba/São Carlos. DOI: http://dx.doi.org/10.5380/dp.v9i1.29096

Nogueira, R. Z. (2019). A Processão do absoluto: notas sobre Merleau-Ponty e Schelling. Princípios - Revista de Filosofia, 26(49), 183-217. DOI: https://doi.org/10.21680/19832109.2019v26n49ID13641

Norsen, T. (2017). Foundations of Quantum Mechanics: An Exploration of the Physical Meaning of Quantum Theory. New York: Springer.

Ramos, S. de S. (2013). A Prosa de Dora: Uma Leitura da Articulação entre Natureza e Cultura na Filosofia de Merleau-Ponty. São Paulo: Edusp.

Sacrini, M. A. F. (2008). Fenomenologia e Ontologia em Merleau-Ponty. Tese de Doutorado em Filosofia - Faculdade de Filosofia, Letras e Ciências Humanas, USP. São Paulo.

Schelling, F. W. J. (1860). System der gesamten Philosophie und der Naturphilosophie insbesonder. In: Sämtliche Werke, VI. Stuttgart/Augsburg: J. G. Cotta'scher Verlag.

Schelling, F. W. J. (1973). Bruno ou Do princípio divino e natural das coisas: um diálogo. In Fichte, J. G.; Schelling, F. W. J. Escritos filosóficos. Ed. e trad. Rubens Rodrigues Torres Filho. Os Pensadores. São Paulo: Abril Cultural.

Schelling, F. W. J. (2004). First Outline of a System of the Philosophy of Nature. Tradução de Keith R. Peterson. New York: State University of New York Press.

Schelling, F. W. J. (2010). Filosofia da Arte. Trad. Márcio Suzuki. São Paulo: Edusp.

Suzuki, M. (2003). La double enigme du monde: nature et langage chez Schelling et Merleau-Ponty. Chiasmi International, 5, 235-258.

Toadvine, T. (2009). Merleau-Ponty's Philosophy of Nature. Illinois: Northwestern University Press.

Uexküll, J. (2006). Mondes animaux et monde humain. Paris: Denoël. 
Rodrigo Benevides Barbosa Gomes

Whitehead, A. N. (1979). Process and Reality: An Essay in Cosmology. Londres/Nova York: The FreePress/ Macmillan.

Whitehead, A. N. (1995). The Concept of Nature. Cambridge: Cambridge University Press.

Whitehead, A. N. (2006). A Ciência e o Mundo Moderno. São Paulo: Editora Paulus.

Recebido em: 27.04.2020

Aceito em: 17.08.2020

\footnotetext{
Esta obra está licenciada com uma Licença Creative Commons Atribuição-NãoComercial-

-Compartilhalgual 4.0 Internacional.

https://creativecommons.org/licenses/by-nc-sa/4.0/
}

(c) (9) (2) 